\title{
Geoeconomia, empreiteiras brasileiras e a integração regional: Atuação do IIRSA o caso do Corredor Viário Interoceânico Sul
}

\section{Geoeconomy, Brazilian construction companies and regional integration: performance in IIRSA in the case of the South Interoceanic Road Corridor}

\section{Geoeconomía, empresas de construcción brasileña y integración regional: actuación en el IIRSA en el caso de la Carretera Interoceánico Sur}

Maria Clara Leadebal Celestino ${ }^{1}$ https://orcid.org/0000-0001-6672-697X

André Santos da Rocha ${ }^{2}$ https://orcid.org/0000-0003-0547-5550

\footnotetext{
${ }^{1}$ Licenciada em Geografia (Universidade Federal Rural do Rio de Janeiro). Membro do Laboratório de Geografia economia e Política (LAGEP/UFFRJ) - Bolsistas de Monitoria de Geografia Economica/ UFRRJ - m.clara1@ hotmail.com

${ }^{2}$ Doutor em Geografia (Universidade Federal do Rio de Janeiro) - Professor da Universidade Federal Rural do Rio de Janeiro e do Programa de Pós-Graduação em Geogarfia (PPGGEO/UFRRJ) - E-mail:asrgeo@ gmail.com
}

Recebido em: 10/07/2020

Aceito para publicação em: 30/11/2020

\section{Resumo}

O artigo apresenta a intima relação entre a integração regional e a geopolítica e geoeconomia, a partir da compreensão do papel das empresas da construção pesada no projeto geoeconômico brasileiro, que obteve espaço de espraiamento das ações na América do Sul com a participação delas em obras do IIRSA. A partir da revisão teórica e de dados sobre as construções, destacamos que as empreiteiras servem como elementos estratégicos de expansão econômica brasileiras, que legitimam as transformações e grandes impactos territoriais. Exemplificamos esse exemplo a partir do caso da construção do Corredor Viário Interoceânico Sul que sintetiza ao mesmo tempo as estratégias, os impactos sociais e ambientais, e o projeto hegemônico do Brasil.

Palavras-chave: Empreiteiras. Integração regional. Geoeconomia Brasileira no IIRSA.

\begin{abstract}
The article presents the intimate relationship between regional integration and geopolitics and geoeconomics, based on the understanding of the role of heavy construction companies in the Brazilian geoeconomic project, which obtained space for the spread of actions in South America with their participation in IIRSA works. Based on the theoretical review and data on constructions, we highlight that contractors serve as strategic elements of Brazilian economic expansion, which legitimize transformations and major territorial impacts. We exemplify this example from the case of the construction of the South Interoceanic Road
\end{abstract}


Corridor that summarizes at the same time the strategies, social and environmental impacts, and the hegemonic project of Brazil.

Keywords: Construction Companies; Regional integration. Geoeconomics Brazilian in IIRSA.

\section{Resumen}

El artículo presenta la íntima relación entre la integración regional y la geopolítica y la geoeconomía, basada en la comprensión del papel de los grandes contratistas de construcción en el proyecto geoeconómico brasileño, que obtuvo espacio para la difusión de acciones en América del Sur con su participación en obras IIRSA. Sobre la base de la revisión teórica y los datos sobre construcciones, destacamos que los contratistas sirven como elementos estratégicos de la expansión económica brasileña, que legitiman las transformaciones y los grandes impactos territoriales. Ejemplificamos este ejemplo del caso de la construcción del la Carretera Interoceánico Sur de que resume al mismo tiempo las estrategias, los impactos sociales y ambientales, y el proyecto hegemónico de Brasil.

Palabras clave: Empresas de Construcción. Integración regional. Geoeconomía brasileña en el IIRSA.

\section{Introdução}

O projeto de Integração da Infraestrutura Regional Sul-Americana [IIRSA] foi originado a partir de um Plano de Ação do Banco Interamericano de Desenvolvimento em uma reunião dos presidentes desta região em Brasília em agosto e setembro do ano de 2000. Assim, concretizou-se o IIRSA em 2002 como um plano que atinge múltiplos setores, integrando transporte, energia e telecomunicação, organizando o espaço geográfico a partir do ideal de desenvolvimento (ZIBECHI, 2006).

A partir disto, essa integração se estruturou a partir de dez eixos de desenvolvimento, sendo eles: Andino, Amazonas, Interoceânico Central, Interoceânico Capricórnio, Escudo das Guianas, Mercosul-Chile, do Sul, Amazônico do Sul e Marítimo do Atlântico e Pacífico. Estes possuíam os objetivos iniciais de integração de mercado intrarregional, redução de custos através de uma logística inserida na economia mundial e conectar cadeias produtivas com os mercados mundiais. É interessante observar que dois dos três objetivos possuem uma escala mundial, e apenas um deles escala regional, ainda que o enfoque da integração seja teoricamente nesta última.

Para concretizar os seus objetivos, o projeto ligaria as áreas de recursos naturais com as grandes cidades, e então com os pontos de exportação. Esse tipo de conduta parece carregar um enfoque em exportação de matérias primas, prática comum entre os países sul-americanos, 
inserindos no "Sistema-Mundo-Moderno-Colonial"

(HAESBAERT;

PORTO-

GONÇALVES,2007) marcadamente na condição de periferia e semi-periferia mundial.

Neste sentido, abrem-se muitos questionamentos: quais sãos impactos do projeto geopolitico e geoeconômico brasileiro na integração para a América do Sul no contexto do mercado global? Quais sãos os projetos de poder inseridos nesta dinâmica de cooperação e integração regional? De que forma, olhar a atuação de empresas brasileiras da construção civil nos ajuda a compreender projetos geoeconômicos brasileiros?

Isto posto, tem-se que o presente artigo tem a proposta de aprofundar-se nas relações estabelecidas entre o IIRSA e as empreiteiras brasileiras com seus projetos na América do Sul, avaliando de como modo participaram de projetos de Integração Regional e quais as transformações territoriais - seja na forma de impacto ambiental, seja de benefício ou prejuízo social. - promovidas por essa associação, apontando também o quanto do projeto geopolítico de expansão econômica territorial foi afetado pela desestruturação das empreiteiras e do próprio IIRSA. Ressalta-se, além disso, que as análises presentes também estarão focadas nos períodos mais atuais, dos anos 2000, desde a idealização do IIRSA, até 2019, para um panorama mais contemporâneo. Para a realização de tais objetivos, propõe-se a investigação histórica dessas relações e posteriormente o estudo dos projetos dessas multinacionais resultantes das propostas do IIRSA, avaliando as condições territoriais delas.

$\mathrm{Na}$ tentativa de responder esses questionamentos, ao menos em parte, apresentaremos as reflexões oriundas do projeto de investigação sobre as estratégias de cooperação Brasileira na América Latina, tomando o caso da participação das Empreiteiras brasileiras de construção pesada, no trecho do Corredor Viário Interoceânico Sul. Partimos da hipótese que esse recorte no contexto do IIRSA permite entender os projetos geoeconômicos Brasileiros, contidos na participação das empreiteiras nas grandes obras de infraestrutura no contexto sulamericano.

Assim, para sistematização das ideias apresentaremos, no primeiro momento, um debate conceitual que busca apontar o entrelaçamento da integração regional com elementos da geoeconomia, tomando o exemplo do caso sulamericano a partir do IIRSA. No segundo momento apresentaremos como o projeto brasileiro se concretiza como uma proposta hegemônica para região [entre os anos 2003-2016], seja como escopo de um subimperialismo, seja como um player econômico que, mesmo com discursos diplomáticos alternativos no contexto das relações Sul$\mathrm{Sul}^{3}$, atua seu expansionismo com o patrocio e investimento de suas grandes empreiteiras. No

\footnotetext{
3 A referência as relações Sul-Sul são fundamentadas na perspectiva diplomática assumida pelo governo brasileiro nas chamadas era Lula-Dilma. Essa perspectiva tinha entre outras características a ações de uma horizontalidade nas negociações e valorização dos acordos com países do Sul Global, que inclui os países da América do Sul.
} 
terceiro momento, destacamos o papel das empresas brasileiras, Odebrecht e Andrade e Gutierrez - do ramo da construção pesada- neste projeto geopolítico e geoeconômico, bem como os impactos decorrentes das obras de infraestrutura, exemplificando as ações no trecho do Corredor Viário Interoceânico Sul. E, por fim, retomamos o debate com algumas indicações nas conclusões.

\section{Integração Regional, Geoconomia e Geopolitica: O Brasil e o IIRSA}

No contexto de um mundo globalizado, entendendo aqui, como o ápice da economia capitalista (SANTOS, 2007), o preceito singular da integração regional faz parte de sua tessitura. Isso ocorre porque a integração assume o papel de conectar lugares, pessoas, lugares de produções-lugares de consumo, e permitir na prática a globalidade do sistema. Desse modo a Integração não é uma coisa, mas um processo. $\mathrm{O}$ codinome regional alimenta um preceito de escala de acontecimento ou ocorrência. A região, como meso-escala revela como o processo da interação une lugares, mas também os fragmenta.

Em termos práticos, se mostra relevante analisar o conceito de Integração Regional, para que seja possível avaliar se esta se mostra coerente no caso do IIRSA. Entende-se por Integração Regional o processo pelo qual uma região se destaca enquanto um sistema distinto dos outros a partir de uma substância social, econômica, cultural, identitária e institucional política (RICHARD, 2014). No entanto, enfoca-se no presente trabalho a vertente econômica, visto que este é o tipo de desenvolvimento visado em primeira instância pelos objetos desta pesquisa. Considera-se então que esta integração econômica envolve mais diretamente uma cooperação em prol da remoção de barreiras ao comércio de bens, capitais, serviços e pessoas (VILELA, 2018).

O processo de Integração regional assume ao menos duas formas. Uma imaterial, que corresponde aos acordos políticos e econômicos que viabilizam a tal integração, aí está organizada, por exemplos as leis e procedimentos, estatutos de organização e normatizas tarifárias. A outra acontece na materialidade deste processo, que uma vez colocada em prática se concretiza nas construções das vias de circulação e conectividade, nos projetos de energia, de transporte e circulação de mercadorias.

O IIRSA se insere neste contexto, uma vez que decorre de uma cooperação entre 12 países da América do Sul, que participam com intensidades e formas diferenciadas. Esse projeto promove a criação, mordenização, ampliação de redes técnicas (redes de transporte, comunicações, energia) que criam novas interações entre os lugares e atende, especificadamente, as demandas dos mercados, uma vez que seu objetivo é potencializar o contato de zonas 
produtoras com áreas de circulação (portos e aeroportos) que busca sobrepor diverentes regiões criadas a partir de grandes eixos de circulação [ver mapa 1]

Mapa 1 - Grandes Eixos de Integração no IIRSA

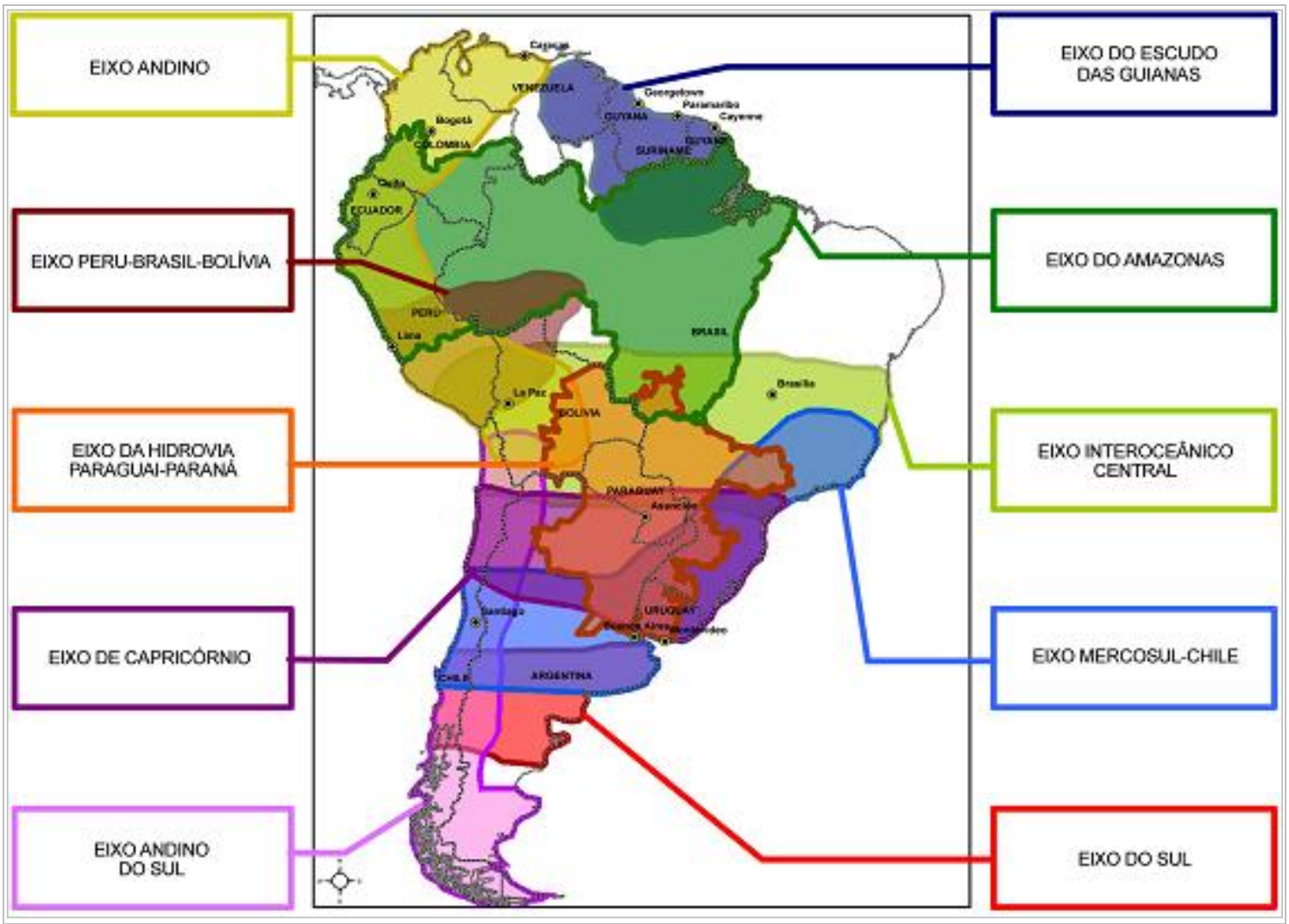

Fonte: CONSIPLAN/ IIRSA. Disponível em < http://www.iirsa.org/admin_iirsa_web/Uploads/

Documents/api_anexo2_projetos_api_mapas_port.pdf> Acesso em : 09/07/2020.

A construção deste projeto de integração regional possui amplo expectro de atuação de atores políticos corroboram para conceber a "América do Sul como uma região geopolítica". Para Rückert e Carneiro Filho (2018) essa concepção é possível a partir das transformações dos quadros políticos na América do Sul, uma ampla atuação da política externa brasileira, sobretudo na era Lula [2003-2010], a incorporação de politicas valorização indentitárias, sem deixar de lado um regionalismo econômico onde a circularidade das mercadorias agragariam valores estratégicos. Ai estaria a clarividência de uma relação íntima entre os projetos de integração regional com elementos estratégicos e projetos de poder.

Se geografia do poder passa por compreender a atuação dos atores (RAFFESTIN,1993), se torna necessário observar que as práticas de participação, financiamento e construção/operacionalização] nos sistemas e projetos de integração regional são partes de uma agenda destes atores que envolve exercícios de poder tanto político quanto econômico. Desta 
maneira, estes atores agem de acordo com os seguintes axiomas: a tessitura dos espaços é rearranjada em um sistema de malhas com diversas possibilidades de decisão, possibilitando assim a formação de uma rede de poder. Assim sendo, o espaço geográfico é esquematizado estrategicamente para os interesses desses atores. No caso estudado, a América do Sul é redesenhada a partir de infraestruturas em prol do desenvolvimento mobilizadas pelos agentes propositores do IIRSA e pelas empreiteiras responsáveis pelas obras a fim de legitimar sua geoeconomia.

Neste sentido, Robert Blackwill e Jannifer Harris (2016) apontam a importância da reflexão sobre o termo geoeconomia, pois o termo indica mais do que uma grafia das relações econômicas. Entre muitas definições, podemos indicar que há uma interconexão do exercício de poder econômico em co-organização de um poder político. Assim, a geoeconomia serve como "instrumento econômico para defender interesses nacionais e produzir resultados geopolíticos benéficos"4 (BLACKWILL; HARRIS, 2016, p.20). Assim, ao observarmos a interceção entre projetos de integração regional, geopolítica e geoceonomia, um ator não necessariamente projeta ações apenas para um tipo de poder (ROCHA, 2019; NYE, 2012) ${ }^{5}$. Em nosso caso de estudo, temos dois atores importantes: a figura do Estado Brasileiro e a figura das empreiteiras brasileira (grandes empresas que atuam na construção pesada).

Em termos operacionais, as Empreiteiras funcionariam como braços "geocômicos do Estado" que trabalhariam na operacilalidade das grandes obras de infraestrutura. Seu crescimento e sua articipação revelam as estratégias de promoção e difusão de capitais públicos e privados Brasileiro na América do Sul. Os Estados nacionais participam como importatente atores nesta trama de poder, porque atuariam com grande ênfase no financiamento dos mega-projetos de inraestrutura do IIRSA, conforme apontra Claudete Vitte (2018, p.56):

Há nos financiamentos utilizados, um aporte majoritário de recursos do setor público (63\% dos investimentos estimados), observando-se que $40 \%$ das obras em execução são financiadas por tesouros nacionais, o que segundo a publicação do BID, Conexión Intal, é uma demonstração do compromisso dos países da América do Sul com a integração física regional.

\footnotetext{
${ }^{4}$ Essa livre tradução de trechoonde é degindo pelos autores a concepção de geoeconomia "The use of economic instruments to promote and defend national interests, and to produce beneficial geopolitical results; and the effects of other nations' economic actions on a country's geopolitical goals" (BLACKWILLS; HARRIS,2016 P.20)

5 Há um amplo debate realizado por Joseph Nye (2012), onde indica que não existe um poder, "mas poderes", pensando esferas e influência e área de atuação: Militar, econômico, político, cultural, cibernético. Para o autor, poderíamos pensar em au menos dois quadros dinâmicos para o exercício de poder: um mais mais duro e impositivo (hard-power) e um poder mais flexível, baseado nas esferas de influência (soft-power). Esses não seriam antagonigos, e operariam hoje em uma imbricação de difícil percepção. O grande exemplo é a lógica do poder econômico, que pode ser exercicdouanto num soft-power quanto num hard-power.
} 
Pensando no caso da atuação do Brasil, como um ator que promove ações geopolíticas e geoeconômicas, para que tudo isso fosse possível, foram necessárias alterações de normas sociais, regulamentos, legislações e elementos físicos. Estes últimos, inclusive, eram vistos exclusivamente como barreiras ou como recursos pelos responsáveis dos grandes bancos envolvidos, como o BID e o BNDES (ZIBECHI, 2006) Averigua-se certa desregulação favorável ao capital neoliberal e às multinacionais responsáveis pelas obras de infraestrutura a partir do alinhamento das legislações referente à atuação destas. Este alinhamento acaba por desconsiderar as particularidades e desigualdades entre os países envolvidos.

A participação das empreiteiras Brasileiras e de seu financiamento advem de interessante antigos de projeção do Brasil na economia-mundo. A participação e financiamento delas por parte do governo brasileiro nas obras do IIRSA assume um caráter estratégico. De acordo com Campos (2010), as empreiteiras brasileiras queixavam-se da concorrência de empresas de países centrais, o que colocava empecilhos em sua internacionalização na região desde que este processo teve início. Assim, projetos como o IIRSA tiveram muita relevância para essas empresas que obtiveram vantagens com os acordos voltados para a infraestrutura entre as nações da América do Sul. Por isso se faz imporantante pensar o papel destas empresas no projeto de poder brasileiro.

\section{Empreiteiras e seu papel no Projeto Brasileiro e sua atuação no IIRSA}

Apesar da internacionalização das empresas brasileiras da construção pesada datarem dos anos 60, estas passaram por muitos altos e baixos, sendo uma dessas quedas a partir dos anos 90, havendo restabelecimento apenas a partir de 2003, juntamente com a recuperação da economia. A expansão das atividades das empresas brasileiras também foi associada aos projetos da Iniciativa de Integração da Infraestrutura Sul-Americana (IIRSA)

No que diz respeito às propostas de construção do IIRSA, Zibechi (2012, p. 236) ressalta que:

Obras como o IIRSA demandam a remoção de barreiras físicas, normativas e sociais para que se realizem grandes obras que harmonizam legislações nacionais dos países implicados. Isto quer dizer "redesenhar a geografia, a legislação dos estados e as relações sociais".

Os projetos do IIRSA foram promovidos pelos governos dos países envolvidos de forma a ser atrativo para a iniciativa privada, estabelecendo a ligação público-privada como um fio condutor de sua materialização. Como exemplo tem-se os investimentos do BNDES que se articularam aos das grandes empreiteiras. 
Algo relevante para consideração é que em 2009 foi criado na UNASUL o Conselho Americano de Infraestrutura e Planejamento (COSIPLAN), que incorporou o IIRSA, que a partir de então não mais receberia diretrizes das agências financeiras multilaterais, mas dos países componentes do bloco. Esta transformação funcionou como resposta a antigas críticas e tem a proposição de uma integração regional que se preocupa com questões político-sociais. Assim, seus objetivos gerais foram modificados para o desenvolvimento de infraestrutura para integração regional, fomento da cooperação estratégica em planejamento e infraestrutura, promoção da compatibilização das normas dos países membros e identificação e impulso na execução de projetos prioritários da integração (COSIPLAN, 2013).

No que se refere ao Plano de Ação Estratégico definido pelo COSIPLAN de 2012 a 2022, com o governo Temer, a partir de 2016, há uma mudança de postura na política externa brasileira no que se refere a sua aproximação com os países da América do Sul, voltando-se então para os países centrais. Isso foi reforçado em 2018, quando a UNASUL teve a participação do Brasil suspensa da mesma, o que também ocorreu com a Argentina, Paraguai, Colômbia e Chile devido a questões políticas com o então secretário-geral da instituição, o que levou a UNASUL a sua inativação (VILELA, 2018).

Assim, vê-se que os objetivos centrados do IIRSA, se voltam para a cooperação regional de fato, além de a integração regional assumir um espectro mais completo, saindo o enfoque do mercado mundial, sendo este definido por Dardot e Laval (2016, p. 280) como um "vasto entrelaçamento movediço de coalizões entre entidades privadas e públicas que se valem de todos os meios e os registros (financeiros, diplomáticos, históricos, culturais, linguísticos etc.) para promover os interesses misturados dos poderes estatais e econômicos".

Neste sentido, pode-se dizer que a dianteira tomada pelo Brasil e suas empresas nessas obras assumiu uma postura subimperialista. Segundo Ryu Mauro Marini (2012), o subimperialismo constitui na adoção de estratégias de expansão no contexto econômico capitalista, sob hegemonia norte-americana, na qual opera a partir da periferia os memso moldes de desnevolvimento engendrados a partir dos países centrais. Neste sentido a projeção econômica Brasileira centrada da expansão de seu poder econômico, associando capitais privados e capitais públicos são considerados por muitos autores como uma materialização desta postura subimperialista.

Entende-se que em termos de integração regional, as empreiteiras brasileiras tiveram um grande papel na materialização dos projetos, o que levou a um aumento exponencial das obras de infraestrutura na região gerenciadas por estas empresas. No entanto, é preciso considerar que a abordagem em prol do desenvolvimento sob a qual esses projetos se sustentam, não é 
acompanhada de uma fiscalização constante, tanto no que se refere às legalidades, quanto no que se refere ao próprio desempenho esperado desses desenvolvimentos, conforme se aponta:

Apesar da intensificação do investimento em empreendimentos de infraestrutura, o desempenho desses projetos tem sido severamente questionado em termos econômicos, de danos ambientais, de legitimidade social e também em relação à escassez dos benefícios esperados. Essa situação é relatada pela literatura como o paradoxo dos megaprojetos, uma vez que o número de grandes empreendimentos de infraestrutura tem aumentado nos últimos anos apesar das diversas falhas e fracassos associados a eles. (PEREIRA, 2018, p. 193)

O projeto de desenvolvimento Brasileiro guarda íntimas relações com a atuação das empreiteiras. Juntamente com a siderurgia, a indústria da construção civil é a mais internacionalizada da economia brasileira, sendo um dos poucos setores a gerar superávit na balança de pagamentos, de acordo com Vasconcellos (2014). São empresas de origem familiar em sua maioria, podendo citar-se entre elas:

- A Odebrecht, fundada em Salvador em 1944 por Norberto Odebrecht;

- A Andrade Gutierrez, criada em 1948 por Flávio Gutierrez, Gabriel e Roberto Andrade em Minas Gerais;

- A Camargo Corrêa, de 1939 em São Paulo por Sebastião Ferraz de Camargo e Sylvio Brant Corrêa;

- A Queiroz Galvão, criada em 1953 situada em Pernambuco por Antônio, Mário e Dário Queiroz Galvão;

- A OAS, de 1976 em Salvador.

Essas empreiteiras se mostram tão relevantes que 40,2\% das obras das empreiteiras brasileiras no exterior entre 1969 e 2010 foram realizadas pela Odebrecht, segundo pesquisas de Campos (2014). Segue-se por 21,5\% da Andrade Gutierrez, 6,5\% da Camargo Corrêa, 4,6\% da Queiroz Galvão e 27,2\% de somatório de outras empresas. Isto demonstra um grau de concentração da indústria - com mais de $70 \%$ dos projetos nas mãos de cinco empresas tão grandes quanto a conhecida concentração fundiária brasileira. Mais uma amostra da tendência monopolista do capitalismo mundial em detrimento de seu momento competitivo anterior.

Como se percebe, a participação da Odebrecht é singular no projeto geoeconômico de poder, vide as ligações existentes deste grupo empresarial com dinâmicas internas da política brasileira. Essa empresa atuou ativamente em ínumeras obras de infraestrutura na América Latina, e diversas etapas e projetos contidos no IIRSA. Após levantamento de dados no site da Odebrechte nas pesquisas de pesquisas de Sposito e Santos (2012), é possível contabilizar a 
atuação da mesma em cerca de 50 projetos, que podem ser sistematizados e visualizados a partir do seguinte do mapa 2.

Mapa 2 - Quantidade e Tipo de Projetos Internacionais da Odebreth [1990-2018]

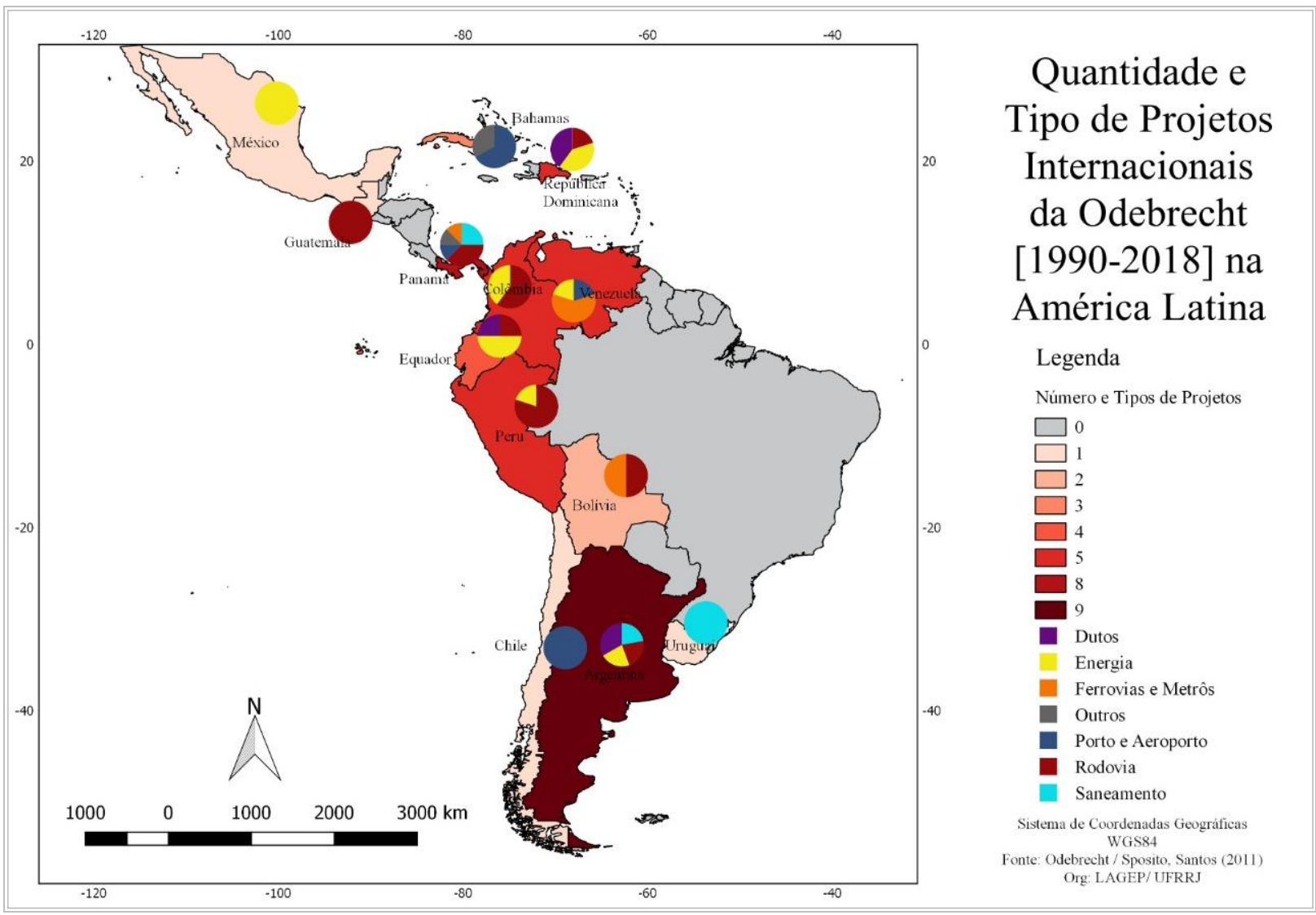

Elaboração: CELESTINO, (2019).

Destacamos a ampla atuação desta empresa em obras de rodovias e de energia, que incluem a construção e reforma de usinas hidrelétricas e gasodutos, por exemplo. Fica muito evidente, inclusive, a relevância desta empresa em termos de entorno estratégico para o Brasil, uma vez que se encontra presente em quase toda a América do Sul, além do México e de países da América Central e do Caribe, que se mostram igualmente estratégicos em termos de integração. Observa-se também no mapa acima que quanto mais projetos há no país, maior é a diversidade de tipos de serviços implantados.

Neste sentido, se torna importante olhar a geoeconomia da atuação desta e de outras empresas nas ações brasileiras do IIRSA, tomadas aqui a partir do corredor Viário Interocênico Sul, que liga o Brasil e o Peru.

\section{A Geoeconomia do Corredor Viário Interoceânico Sul}

Para que se compreenda tais questões territorialmente e as relações das propostas do IIRSA com as empreiteiras brasileiras em especial da atuação da Odebrecht e da Andrade e Gutierrez, 
propõe-se um estudo de caso do Corredor Viário Interoceânico Sul, que interconecta estradas do Peru e Brasil. "O corredor liga a fronteira brasileira com três portos peruanos: San Juan de Marcona, Matarani e Ilo, sendo a rota Iñapari - Ponte Inambari - Azángaro - Juliaca - Matarani”6 . Esse corredor está inserido no Eixo do Amazônas do IIRSA que interconecta o Brasil, Peru, Colombia e Equador [ver mapa 3]

Mapa 3 - Eixo Amazonas

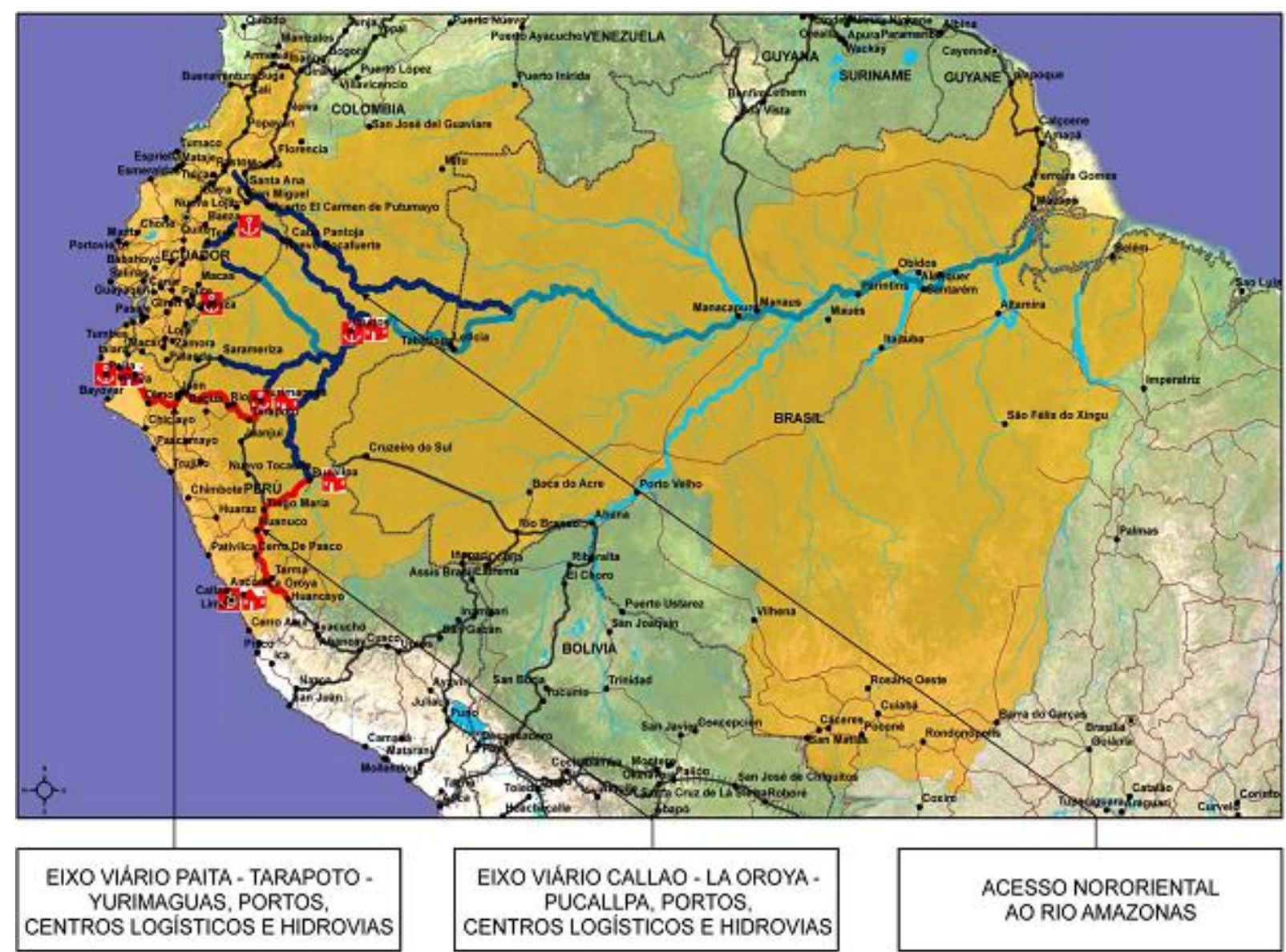

Fonte: CONSIPLAN/ IIRSA. Disponível em <

http://www.iirsa.org/admin_iirsa_web/Uploads/Documents/api_anexo2_projetos_api_mapas_port.pdf > Acesso em : 09/07/2020.

O referido eixo possui ampla atuação brasileira em obras que busca atender uma demanda antiga da geopolítica e geoeconômia brasileira que emanda no processo de integração regional da porção norte do país. Além disso, essa região de integração possui proximidade com o eixo Interoceânico Central. Esse segundo permite o acesso ao ocêano Pacífico, que viabilizará concetividades de zonas produtivas brasileiras (industriais e do agronegócio) aos mercados asiáticos. Por isso, é importantíssimo a conexão das cidades brasileiras com os portos peruanos.

\footnotetext{
6 Informação disponibilizada pela Andrade Guitierrez em seu web-site. < http://andradegutierrez.com.br/Projetos/InteroceanicaSul.aspx > Acesso em 09/07/2020
} 
De acordo com Dourojeanni (2006), houve um financiamento parcial da Corporação Andina de Fomento (CAF) com garantia pela República do Peru. Segundo reportagem da agência EFE, “o complexo viário interoceânico, que recebeu US\$ 1,6 bilhão investidos pelos governos do Brasil e do Peru"?.

No fim de junho de 2010 a Odebrecht inaugurou no Peru o trecho 3 do Corredor Viário Interoceânico Sul, que que em completude liga Cusco à Iñapari, na fronteira com o Brasil (ODEBRECHT, 2010). Juntamente com o trecho 2 finalizado anteriormente, esta obra foi realizada em consórcio com a Graña y Montero, JJC Contratistas Generales e ICCGSA. Todas estas empresas são peruanas, destacando-se, no entanto, a primeira por ser a maior delas, além de ter um histórico de envolvimento em escândalos de corrupção, inclusive com a parceira do Consórcio Conirsa, a Odebrecht ${ }^{8}$.

Já em 2011, a Andrade Gutierrez ficou responsável pela realização das obras no trecho 4 do projeto, também chamado de Corredor Viário IIIRSA Sul. Este trecho integraria o Brasil com os Portos Peruanos no Pacífico e o Peru com os mercados do Brasil, sendo instalada em uma área acidentada de condições geológicas, topográficas e climáticas variadas (ANDRADE GUTIERREZ, 2011).

Em relação aos impactos avaliemos primeiramente que sendo seu principal objetivo a interconexão logística de mercado, é preciso considerar que o transporte de cargas é ainda muito dependente de combustíveis fósseis, o que contribui para a emissão de poluentes. Além disso, afeta diretamente a Amazônica peruana e, portanto, sua biodiversidade e povos indígenas. É preciso considerar que a rodovia aumenta o efeito de borda, isto é, os impactos gerados a partir das extremidades de contato da biodiversidade com as ações antrópicas. Assim, aumenta-se a velocidade do desmatamento nestas áreas, além de invasão de áreas protegidas, aproximação de povos indígenas de isolamento voluntário, influência nas dinâmicas dos recursos hídricos, entre outros. Além de tudo, ainda propagou-se que os impactos seriam reduzidos pelo fato de muitas partes da rodovia já existirem e serem apenas reformadas, no entanto, há um aumento de circulação para as obras, novos recursos são mobilizados, e inicialmente se quer houve um programa de limitação de danos (DOUROJEANNI, 2006).

Neste sentido é interessante avaliar que as relações do Brasil com o Peru foram reforçadas em 2003 pela Aliança Estratégia Peru-Brasil com os objetivos principais de complementação

\footnotetext{
${ }^{7}$ Informação disponível < https://noticias.uol.com.br/ultimas-noticias/efe/2010/11/04/interoceanica-permiteintegracao-com-outros-paises-afirma-ministro-peruano.jhtm> Acesso em 09/07/2020

${ }^{8}$ Executivos do Graña y Monteiro alegaram saber das propinas da Odebrecht para o ex-presidente Alejandro Toledo, que negou a acusação. Notícia disponível em: https://epocanegocios.globo.com/Empresa/noticia/2017/02/epocanegocios-empreiteira-peruana-grana-y-montero-demite-executivos-em-meio-a-escandalo-de-corrupcao.html.
} 
econômica Mercosul-Peru, vigilância da Amazônia para conservação de fauna e flora e a integração física e econômica com o IIRSA (LOPEZ, 2017). Destaca-se então a sobressalência da realização deste último, mesmo que em detrimento de outros como a própria questão amazônica que foi diretamente afetada pelas construções promovidas pelo IIRSA, como colocado anteriormente.

De acordo com Ana Karine Pereira (2018), em termos econômicos, projetos de infraestrutura tem tido seus custos aumentados até mesmo pelos atrasos de cronograma; em termos ambientais, os impactos têm sido mal calculados; em sociais, as vantagens locais e regionais dificilmente são passíveis de mensuração, além do afastamento geral da sociedade, uma vez que a transparência é dada de forma limitada pelos gestores.

No que se refere à força de trabalho empregada nas obras promovidas pelas empreiteiras brasileiras nos demais países da América do Sul, tem-se que os trabalhadores não qualificados são majoritariamente os locais da região da obra, enquanto os qualificados são brasileiros ou estrangeiros à América do Sul. Também ocorrem subcontratações de firmas locais em uma política de boa vizinhança que acaba por baratear a obra, uma vez que há menos necessidade logística (CAMPOS, 2010).

Dessa forma, é possível falar em fortalecimento mútuo empresarial na região, ainda que não seja um crescimento proporcional, já que as grandes empreiteiras lucram bem mais que as firmas locais. No entanto, não é possível falar em crescimento igual para as forças de trabalho envolvidas, uma vez que não se investe na mão de obra qualificada da região selecionada.

Dentre os principais impactos comuns a essas obras, é a acumulação por espoliação (HARVEY, 2005) dessas empresas. Os grupos sociais têm seu modo de vida e relação com o território transformado definitivamente. Isto se dá uma vez que os ritmos econômicos impostos não são compatíveis com os interesses reais dessas populações. Nesse contexto, apesar de uma opinião pública positiva devido às propagandas pelo desenvolvimento econômico, tem-se o aumento da migração de populações andinas a partir das obras, aumento dos conflitos de terra e desenvolvimento de pobreza urbana, além das perdas culturais e tradicionais.

Além disso, com a Operação Lava Jato, muitas das maiores empreiteiras brasileiras ficaram comprometidas em relação à sua credibilidade internacional. Esta operação foi iniciada em março de 2014 e se refere a um conjunto investigações de lavagem de dinheiro e corrupção ${ }^{9}$, cujas

\footnotetext{
${ }^{9}$ Entende-se por corrupção no presente artigo as práticas de enfoque econômico político público-privado caracterizadas pela falta de aplicação da legalidade em prol de relações econômicas, transgressão dos padrões éticos pelo não cumprimento das normativas em detrimento da sociedade, desvio de função e violação direta de regras para obtenção de benefício pessoal. Para mais detalhes sugerimos ver (LOPEZ, 2017).
} 
informações compartilhadas por meio de acordos de cooperação internacional foi o estopim para que mais doze países relacionados iniciassem suas próprias investigações ${ }^{10}$.

Dentre as empresas envolvidas estavam a Odebrecht, chegando os escândalos desta ao Peru em 2016 através da denúncia de subornos por contratos e licitações. Neste caso, estava envolvido as rotas 2 e 3 do Corredor Viário Interoceânico Sul, proposta diretamente relacionada ao IIRSA. Sendo assim, é evidente que este último também tem sua confiabilidade abalada.

É possível visualizar assim que a integração regional promovida, mais que apenas a economia, integra impactos ambientais, conflitos de interesse social e questões políticas e legais.

\section{Considerações Finais}

A compreensão dos projetos de poder da agenda brasileira para América da Sul demanda entender as relações geoeconômicas, portanto, é necessário compreender o papel de suas empresas em dois processos. O primeiro é de expansão do poderio do capital nacional via essas empresas, que ganham força e solidez, e participam como braço ativo e estratégico do expansionismo nacional sob um caráter subimperialista, $\mathrm{O}$ segundo, é que estas servem como braço operacional na viabilização de marcos geopolítico e geoeconômica o viabiulizarem com sua força e técnicas, a conscretização das vias de integração que servem como conectores que atendem demandas de inserção de suas regiões aos mercados globais, bem como para articulação da interiorização e controle de territórios.

O IIRSA, em suas múltiplas etapas e eixos de integração servem para expressar ao mesmo tempo uma iniciativa regional de liderança da América do Sul em prol de uma inserção aso mercados globais, quando a posturas interesse geopolíticos dos Estados. No Cado Brasileiro, o exemplo da construção do Corredor Viário Interoceânico Sul, serve a geoeconomia brasileira no sentido de garantir acesso ao oceano Pacífico e a respectiva integração das zonas produtivas brasileiras aos mercados asiáticos bem como garantir a integração com as porções norte do país, como garantir influência junto aos países vizinho da América Andina.

A noção de geoeconomia se torna vital para traduir os projetos de poder que interssionam elementos do campo econômico e do campo político.

Por fim, compreende-se a partir do acaso apresentado a necessidade de aprofundamento das intepretações sobre as relações geoeconômicas brasileiras na América do Sul, bem como

\footnotetext{
${ }^{10}$ Para mais detalhes, consultar Ministério Público Federal em http://www.mpf.mp.br/grandes-casos/lavajato/entenda-o-caso. 
reconhecermos o papel orgânico das empreiteiras no processo interno político e econômico do país e de sua atuação na expansão do Brasil na economia mundo.

\section{Referências}

ANDRADE GUTIERREZ. Rodovia Interoceânica Sul. 2011. Disponível em: http://www.andradegutierrez.com.br/Projetos/InteroceanicaSul.aspx . Acesso em: 13 de Abril de 2020.

BLACKWILL.R.D.; HARRIS, J.M. War by other means: geoeconomics and statecraft. Harvard University Press: London, 2016.

BRASIL. Caso Lava Jato: Entenda o Caso. Ministério Público Federal, Brasília. Disponível em: http://www.mpf.mp.br/grandes-casos/lava-jato/entenda-o-caso. Acesso em: 17 de Abril de 2020.

CAMPOS, P. H. P. A transnacionalização das empreiteiras brasileiras e o pensamento de Ruy Mauro Marini. In: Contra a Corrente: revista marxista de teoria, política e história contemporânea. Vol. 2, 2010. p. 70-77.

CELESTINO, M.C.L. Cooperação econômica entre o brasil e os demais países da américa latina [1990-2018]: a geografia dos fluxos de investimento direto e das multinacionais brasileiras da construção civil. Monografia de Graduação apresentado no Departamento de Geografia da Universidade Federal Rural do Rio de Janeiro. 2019, 83p.

COSIPLAN. Objetivos. Estatuto, Anexo 1. 2013. Disponível em: http://www.iirsa.org/Page/Detail?menuItemId=120. Acesso em: 9/04/2020.

DARDOT, P.; LAVAL, C. A Nova Razão do Mundo: Ensaio sobre a Sociedade Neoliberal. $1^{\text {a }}$ ed. São Paulo: Boitempo, 2016.

DOUROJEANNI, M. A Estrada Interoceânica no Peru. O Eco, 20 de junho de 2006. Disponível em: https://www.oeco.org.br/colunas/marc-dourojeanni/16394-oeco-17257. Acesso em: 13/04/2020.

HAESBAERT, R. PORTO-GONÇALVES. C.W. A Nova (des)ordem Mundial. São Paulo: EDUNESP, 2006

LOPEZ, A. P. S. Odebrecht y La IIRSA Norte y Sur: Un Caso De Corrupción Y Su Influencia En Las Relaciones Bilaterales Con Perú En Infraestructura Durante Los Años 2005-2007. Tese (Mestrado em Ciência Política e Governo) na Pontificia Universidad Católica del Peru. Lima, 2017.

MARINI, R. M. Subdesenvolvimento e revolução. 3ªed. Florianópolis: Editora Insualar, 2012.

NYE. J. O futuro do Poder. São Paulo: Benvirá, 2012.

ODEBRECHT. Novo trecho do Corredor Interoceânico Sul é inaugurado no Peru. Notícias, 19 de julho de 2010. Disponível em : https://www.odebrecht.com/pt-br/novo-trecho-do-corredorinteroceanico-sul-e-inaugurado-no-peru . Acesso em: 13/04/2020. 
PEREIRA, A. K. As Políticas de Infraestrutura no Brasil e o paradoxo das grandes Obras: estudos de caso de empreendimentos do programa de aceleração do crescimento. In: GOMIDE, A.; PEREIRA, A. K. (ed.) Governança da Política de Infraestrutura: Condicionantes Institucionais ao Investimento. Rio de Janeiro: IPEA, 2018. 449 p.

RAFFESTIN, C. Por uma geografia do poder. São Paulo: Ática (1993 [1980]).

REUTERS. Empreiteira peruana Grana y Montero demite executivos em meio a escândalo de corrupção. Época Negócios, 28 de Fevereiro de 2017. Disponível em:

https://epocanegocios.globo.com/Empresa/noticia/2017/02/epoca-negocios-empreiteira-peruanagrana-y-montero-demite-executivos-em-meio-a-escandalo-de-corrupcao.html Acesso em: $13 / 04 / 2020$

RICHARD, Y. Integração regional, regionalização, regionalismo: as palavras e as coisas. São Paulo: Confins, $n^{\circ}$ 20, 2014.

RÜCKERT, A.; CARNEIRO FILHO, C. P. "Políticas territoriais na América do Sul: infraestruturas de conexão e repercussões em regiões periféricas". In: RÜCKERT, A. A.; SILVA, A. C. P. da; SILVA, G. de V. (Orgs.). Geografia Política, Geopolítica e Gestão do Território: integração sul-americana e regiões periféricas. Porto Alegre: Editora Letra1, 2018, p. 11-39. Disponível em: https://editoraletra1.com.br/epub/9788563800367/files/9788563800367-01.pdf, Acesso em 15/05/2019.

ROCHA. A. Poder e cooperação internacional nos estudos de geopolítica. In: SENHORA, E; VITTE, C.; ROCHA, A. S. (Org.). Geografia e Relações Internacionais. Debates Temáticos! Boa Vista (RR): UFRR, 2019, v. 1, p. 71-90.

SPOSITO, Eliseu Savério. SANTOS, Leandro Bruno. O Capitalismo Industrial e as Multinacionais Brasileiras. Outras Expressões, $1^{a}$ Ed. São Paulo, 2012.

SANTOS. M. Por uma outra Globalização. $3^{\circ}$ ed. Record: São Paulo, 2007.

VILELA, M. S. P. T. Da IIRSA ao COSIPLAN: A Política Externa Brasileira dos governos Lula (2003 - 2010) e a Integração da Infraestrutura Regional da América do Sul. Trabalho de Conclusão de Curso (Bacharelado) - Instituto de Economia e Relações Internacionais da Universidade Federal de Uberlândia, Uberlândia, 2018.29f.

VITTE, C. C. S. "Integração da infraestrutura produtiva na américa do sul sob a coordenação do Cosiplan/Unasul: financiamento e planejamento territorial". In: RÜCKERT, A. A.; SILVA, A. C. P. da; SILVA, G. de V. (Orgs.). Geografia Política, Geopolítica e Gestão do Território: integração sul-americana e regiões periféricas. Porto Alegre: Editora Letra1, 2018, p. 51-67. Disponíevl em: https://doi.org/10.21826/9788563800367-03 . Acesso:15/04/ 2020.

ZIBECHI, R. IIRSA: la integracióna la medida de los mercados. Ecología Política: Megainfraestructuras, $n^{\circ} 31$. Novembro de 2006. p. 19-25.

ZIBECHI, R. Brasil Potência: Entre a Integração Regional e um Novo Imperialismo. Rio de Janeiro: Consequência, $2^{\mathrm{a}} \mathrm{ed}, 2012.333$ p. 


\section{Agradecimentos}

Este material é subproduto da pesquisa denvolvida no âmbito do Laboratório de Geografia econômica e Política a qual agradece o apoio recebido da Pro-Reitoria de Pesquisa e Pós-Graduação da UFRRJ e ao CNPq. Agradeçemos em especial a FAPERJ pela concessão da Bolsa de IC [2018-2019] à Maria Clara Celestino Laudebal para realização da pesquisa. 